\title{
Sertraline induced acute mandibular dystonia
}

\author{
Dhanya Raveendranathan, Swaminath Gopala Rao \\ Department of Psychiatry, Dr. B. R. Ambedkar Medical College, Bengaluru, Karnataka, India
}

\begin{abstract}
Specific serotonin reuptake inhibitors have been linked with the occurrence of drug-induced parkinsonism, dystonia, dyskinesia, and akathisia. Here, we describe a patient with a diagnosis of emotionally unstable personality disorder and depression who developed severe mandibular dystonia with sertraline in the absence of concurrent prescription of medications, which have potential action on the dopaminergic system. This case highlights the need for clinicians to be aware of this alarming acute adverse effect with sertraline, which is conventionally considered to be well-tolerated and safe.
\end{abstract}

Key words: Dystonia, extrapyramidal symptoms, selective serotonin reuptake inhibitors, sertraline

\section{Introduction}

Selective serotonin reuptake inhibitors (SSRIs) are considered to be efficacious and relatively well-tolerated. Even though the neurological side effects with SSRI are less common, they are presumably also less reported. ${ }^{[1]}$ SSRIs have been linked with the occurrence of drug-induced parkinsonism, dystonia, dyskinesia, and akathisia. Sertraline is an SSRI, which has been previously reported to have associated extrapyramidal adverse effects such as akathisia and dystonia. ${ }^{[2]}$ Though advancing age has been reported to be a risk factor for SSRI-induced extrapyramidal adverse effects, sertraline has been reported to have caused oromandibular dystonia in an adolescent patient. ${ }^{[3]}$ There is a previous report of mandibular dystonia occurring with sertraline, which was prescribed concomitantly with metoclopramide (a dopamine antagonist). ${ }^{[4]}$ Here, we describe a patient who developed severe mandibular dystonia with sertraline in the absence of concurrent prescription of medications which have potential action on the dopaminergic system.

\section{Address for correspondence:}

Dr. Dhanya Raveendranathan, Department of Psychiatry,

Dr. B. R. Ambedkar Medical College, Kadugondanahalli,

Bengaluru - 560 045, Karnataka, India.

E-mail: dhanya.ravi@gmail.com

\begin{tabular}{|l|l|}
\hline \multicolumn{2}{|c|}{ Access this article online } \\
\hline Quick Response Code: & Website: \\
\hline & www.ruralneuropractice.com \\
\hline & \\
\hline
\end{tabular}

\section{Case Report}

A 25-year-old single female with a temperamental history of mood swings and low frustration tolerance was on treatment for emotionally unstable personality disorder-impulsive sub-type. She had a past history of two impulsive self-harm attempts of low intentionality and lethality. Oxcarbazepine $300 \mathrm{mg}$ once daily was started for her marked and unpredictable mood fluctuations. Currently, she presented with a depressive episode of 2 months duration characterized by low mood, lack of interest, ideas of hopelessness, and anhedonia. Her physical examination findings were within normal limits. She did not have significant preexisting medical or neurological illnesses. Her metabolic profile, liver, and renal function tests were within normal limits. Sertraline $50 \mathrm{mg}$ once daily was started while continuing oxcarbazepine $300 \mathrm{mg} /$ day. Within 2 days of starting treatment, she began to experience frequent episodes of sustained involuntary opening of jaw lasting for about 2-3 min each time suggestive of mandibular dystonia. These episodes would recur multiple times daily and were extremely distressing in nature. Tablet sertraline was stopped quickly while continuing oxcarbazepine. This was followed by immediate and complete resolution of dystonia. The Naranjo probability score of 6 suggested a relationship between sertraline use and this

This is an open access article distributed under the terms of the Creative Commons Attribution-NonCommercial-ShareAlike 3.0 License, which allows others to remix, tweak, and build upon the work non-commercially, as long as the author is credited and the new creations are licensed under the identical terms.

For reprints contact: reprints@medknow.com

How to cite this article: Raveendranathan D, Rao SG. Sertraline induced acute mandibular dystonia. J Neurosci Rural Pract 2015;6:586-7. 
adverse event. ${ }^{[5]}$ Subsequently, the patient was started on mirtazapine $15 \mathrm{mg} /$ day and there was no recurrence of dystonia. The depressive symptoms became better and she improved significantly over 1-month.

\section{Discussion}

In this case, the patient developed acute mandibular dystonia with sertraline, and there were no other medications with known effect on the dopaminergic system. The patient was on oxcarbazepine, which has not been associated with extrapyramidal symptoms previously. Drugs which cause variations in the pharmacokinetic factors such as cytochrome 4450 enzyme CYP2D6 have been known to increase vulnerability to adverse effects like dystonia. ${ }^{[6]}$ However, oxcarbazepine is metabolized with different liver enzymes and hence this is unlikely to be due to drug-interaction related factors.

The basal ganglia have been reported to be an area of dysfunction in dystonia. A possible role for cerebellum has also been reported. ${ }^{[7]}$ The etiological factors for dystonia include genetic predisposition, secondary causes such as peripheral traumatic or surgical incidents, neurological disorders and drugs mainly antipsychotics. ${ }^{[7,8]}$ The most common form of dystonia is tardive dystonia due to antipsychotic usage.

A review of extrapyramidal manifestations demonstrates that dystonia can also occur with SSRIs including sertraline. ${ }^{[6]}$ It has been hypothesized that SSRI-induced extrapyramidal side effects are probably due to the inhibitory effect, which the serotonergic inputs have on the dopaminergic pathways in the striatum. ${ }^{[9]}$

Oral medication is the usual first line of treatment. Commonly used medications are anticholinergic agents, benzodiazepams, antiparkinsonism drugs, anticonvulsants, baclofen, carbamazepine, and lithium. Anticholinergic medications have been found to be the most effective oral medication, especially when prescribed in early stages. ${ }^{[8]}$ Botulinum toxin injection is the next line of treatment, especially preferred in focal dystonia. Botulinum toxin blocks acetylcholine release at the presynaptic junction, producing a transient weakening of the muscle activity without systemic effects. It can be immunogenic, and there are rare reports of patients becoming immune-resistant with multiple injections. Muscle afferent block, by intramuscular injection of anesthetic and alcohol, has also been used for treatment. ${ }^{[8]}$

In this case, the resolution of dystonia after discontinuation of sertraline and the Naranjo scale indicates a causal relationship. It specifically highlights the need for clinicians to be aware of this alarming acute adverse effect with sertraline, which is conventionally considered to be well-tolerated and safe.

\section{Financial support and sponsorship}

Nil.

\section{Conflicts of interest}

There are no conflicts of interest.

\section{References}

1. Leo RJ. Movement disorders associated with the serotonin selective reuptake inhibitors. J Clin Psychiatry 1996;57:449-54.

2. Walker L. Sertraline-induced akathisia and dystonia misinterpreted as a panic attack. Psychiatr Serv 2002;53:1477-8.

3. Sarısoy S, Özyürek H, Sarisoy G. Oromandibular dystonia associated with sertraline in an adolescent patient. Bull Clin Psychopharmacol 2012;22:83-5.

4. Christensen RC, Byerly MJ. Mandibular dystonia associated with the combination of sertraline and metoclopramide. J Clin Psychiatry 1996;57:596.

5. Naranjo CA, Busto U, Sellers EM, Sandor P, Ruiz I, Roberts EA, et al. A method for estimating the probability of adverse drug reactions. Clin Pharmacol Ther 1981;30:239-45.

6. Madhusoodanan S, Alexeenko L, Sanders R, Brenner R. Extrapyramidal symptoms associated with antidepressants - A review of the literature and an analysis of spontaneous reports. Ann Clin Psychiatry 2010;22:148-56.

7. Gonzalez-Alegre P, Schneider RL, Hoffman H. Clinical, etiological, and therapeutic features of jaw-opening and jaw-closing oromandibular dystonias: A decade of experience at a single treatment center. Tremor Other Hyperkinet Mov (N Y) 2014;4:231.

8. Maestre-Ferrín L, Burguera JA, Peñarrocha-Diago M, Peñarrocha-Diago M. Oromandibular dystonia: A dental approach. Med Oral Patol Oral Cir Bucal 2010;15:e25-7.

9. Gill HS, DeVane CL, Risch SC. Extrapyramidal symptoms associated with cyclic antidepressant treatment: A review of the literature and consolidating hypotheses. J Clin Psychopharmacol 1997;17:377-89. 